\title{
The epidemiology of headaches among patients with epilepsy: a systematic review and meta-analysis
}

\author{
Bereket Duko* ${ }^{*}$, Mohammed Ayalew and Alemayehu Toma
}

\begin{abstract}
Background: Headache is the symptom of pain in the face, head or neck that causes disability in most people with medical and neurological disorders. It frequently co-occurs with most chronic diseases such as epilepsy and significantly impacts the quality of life. However, epidemiologic data from different studies showed different rates of prevalence. Therefore, we conducted this review to summarize the available epidemiologic evidence on the topic and formulate recommendations for future research and clinical practice.

Methods: We followed the preferred reporting items for systematic review and meta-analysis (PRISMA) guidelines. We systematically searched the literature using popular databases such as PubMed, EMBASE, Psych-INFO, and SCOPUS. We further scanned the reference lists of the eligible studies to supplement our electronic search. The Comprehensive MetaAnalysis software version 3.0 (CMA 3.0) was used to conduct a meta-analysis. Subgroup and sensitivity analysis were performed and Cochran's Q- and the $I^{2}$ - test were used to assess the source of heterogeneity. The funnel plot and Egger's regression tests were used to assess potential publication bias.

Results: A total of 17 studies conducted both in developed and developing countries including 5564 study participants were combined in this meta-analysis. The pooled estimated prevalence of headache among patients with epilepsy was 48.4\%. The pooled estimated prevalence of Inter-Ictal headache $(\mathrm{IIH})(42.2 \%)$ and Postictal headache $(\mathrm{PIH})(43.1 \%)$ were higher when compared to tension-type headache (TTH) (26.2\%), migraine with aura (26.0\%) and migraine without aura (10.4\%). The pooled prevalence of headache was $50.6 \%$ and $49.5 \%$ for developed and developing countries respectively. The pooled prevalence of headache among patients with epilepsy was considerably higher among females (63.0\%) when compared to males (33.3\%). Moreover, the pooled estimated prevalence of headache among patients with epilepsy was ranging from $46.0 \%$ to $52.2 \%$ in a leave-one-out sensitivity analysis.
\end{abstract}

Conclusion: The pooled estimated prevalence of headache among patients with epilepsy was considerably high (48.4\%). Screening and appropriate management of headaches among patients with epilepsy are warranted.

Keywords: Prevalence, Headaches, Epilepsy, Seizure, Systematic review, Meta-analysis

\section{Background}

Neurological disorders are emerging challenges to health care systems and requiring further study, government as well as social engagement, and improvements in health care infrastructure [1]. Epilepsy is one of the neurologic disorders which is characterized by repeated seizure attacks which result from paroxysmal uncontrolled discharges of neurons [2-5]. The World Health Organization

\footnotetext{
* Correspondence: berkole.dad@gmail.com

College of Medicine and Health Sciences, Hawassa University, Hawassa,
} Ethiopia

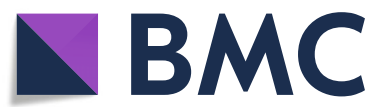

(0) The Author(s). 2020 Open Access This article is distributed under the terms of the Creative Commons Attribution 4.0 International License (http://creativecommons.org/licenses/by/4.0/), which permits unrestricted use, distribution, and reproduction in any medium, provided you give appropriate credit to the original author(s) and the source, provide a link to the Creative Commons license, and indicate if changes were made. defines epilepsy as having two or more unprovoked seizures [2].

Epilepsy affected around 50 million people worldwide in 2019 [2]. Of these, $80 \%$ of people with epilepsy live in low- and middle-income countries [2, 6, 7]. A systematic review and meta-analysis conducted in 2017 reported that the point prevalence of active epilepsy was 6.38 per 1000 persons while the lifetime prevalence was 7.60 per 1000 persons [8]. Further, the annual cumulative incidence of epilepsy was 67.77 per 100,000 persons while the incidence rate was 61.44 per 100,000 person-years 
[8]. Finding from another study also revealed that the lifetime incidence of epilepsy is ranging from 1 to 26 with a peak age ranges from 30 to 50 years [9].

Headache is the symptom of pain in the face, head, or neck that causes disability in most people with medical and neurological disorders [10]. There are different types of headaches that can occur in individuals but generally can be classified as primary and secondary headaches [11]. Primary headaches broadly include migraines and tension-type headaches [12]. Migraines are characterized by pulsing head pain, nausea, and sensitivity to light and sound whereas tension-type headaches present with non-pulsing "band-like" pressure on both sides of the head but not accompanied by other symptoms [13].

Headache frequently co-morbid with most chronic diseases such as epilepsy [14-17]. For instance, a review conducted to see the relationship between headache and epilepsy reported the comorbidity of headache and epilepsy as a result of common genetic mutations and clinical features $[18,19]$, but the suggested link is not revealed conclusive evidence of a real causal association [20]. Further, studies also suggested that there are genetic relationships [19] as well as common underlying pathophysiological mechanisms including the imbalance between excitatory and inhibitory neurotransmitters in epilepsy and headache, especially for migraine [18, 21]. Proposed theories for shared etiologies include ion channel dysfunction, glutamatergic mechanisms, and mitochondrial dysfunction $[22,23]$. These suggest that the cause of headache and epilepsy are multifactorial and hence need different diagnostic and interventional approaches [24].

Epidemiologic evidence from different studies reported different rates of prevalence of headache among epileptic patients $[25,26]$. For example, a cross-sectional study conducted in China to assess the prevalence of headache among patients with epilepsy reported $60.1 \%$ [25]. In contrast, a study assessed the prevalence of headache among epileptic patients in Japan revealed 23\% [26]. Thus, estimating the burden of headaches among patients with epilepsy is critically important. Even though a systematic review and meta-analysis has been conducted in 2017 on a similar area of study [27], however, it only assessed the comorbid relationship between migraine and epilepsy [21]. In spite of that, the current review tried to investigate the pooled prevalence of headaches such as migraine, tension-type headaches, and others among patients with epilepsy to summarize the available epidemiologic evidence on the topic and formulate recommendations for future research as well as clinical practice.

\section{Methods}

\section{Study design and search process}

This systematic review and meta-analysis followed the preferred reporting items for systematic review and meta-analysis (PRISMA) guidelines [28]. We reviewed research articles that assessed the prevalence of headaches among patients with epilepsy. We systematically searched the literature using common databases such as PubMed, EMBASE, Psych-INFO, and SCOPUS. Medical Subject Headings (MESH) terms were used to perform the electronic database search in PubMed: "headache OR migraine OR tension-type headache OR Headache on seizure-day OR postictal headache OR ictal headache OR primary headaches OR cluster headaches) AND (prevalence OR magnitude OR epidemiology OR incidence)) AND (Epilepsy OR Seizure disorder OR convulsion OR seizure attack OR paroxysm)". The EMBASE, Psych-INFO, and SCOPUS databases were also comprehensively searched by applying the search terms used in PubMed for each database accordingly. Further, we also boosted our literature search through a manual search of the reference lists of eligible articles.

\section{Eligibility criteria}

Studies were included in the review if they fulfill the following inclusion criteria: observational studies including cross-sectional design; conducted among patients with epilepsy or seizure disorders, studies that were published in the English language and determined the prevalence of primary headaches among patients with epilepsy. However, we excluded commentaries, letters, duplicate studies, editorials, reviews, and short communications as they did not satisfy the eligibility criteria.

\section{Methods for data extraction and quality assessment}

The data extraction from the relevant studies was employed by two independent reviewers. We extracted the following information from each study: the name of the first author, the year of publication, study setting, and design, sample size, prevalence, and tools used to estimate the magnitude of AUD, type of headaches reported and the reported magnitude by gender of the participants. Disagreements raised during data extraction were solved by discussion. The Newcastle-Ottawa Scale (NOS) was used to check the quality of the included studies in the meta-analysis [29, 30]. The data measurement tools used to assess types of headaches, sample size, methodological quality, types of headache, sample representativeness and comparability between participants were the domains of the NOS scale to assess the quality of the included studies.

\section{Definition of terms}

Headache is the symptom of pain in the face, head, or neck that causes disability in most people with medical and neurological disorders [10]. In this review, headache was considered when the studies investigated and reported the prevalence of primary headaches such as 
migraine (with or without aura), tension-type headache, Ictal headache, and post-ictal headache among patients with epilepsy based on any standardized and validated screening instruments used to assess headaches such as Migraine Screening -Questionnaire (MSQ), the International Classification of Headache Disorders 2nd or 3rd edition (ICHD-2, 3), the Headache-Attributed Lost Time (HALT) and the six-item Headache Impact Test.

\section{Data synthesis and analysis}

A meta-analysis was conducted by a Comprehensive Meta-Analysis software version 3.0 (CMA-3.0). The random-effect model for meta-analysis was employed to pool the overall prevalence of primary headaches among patients with epilepsy. The magnitude of statistical heterogeneity between the eligible articles was checked by Q-statistic and the $\mathrm{I}^{2}$-statistics [31] and values of 25, 50 and $75 \%$ were used to represent low, medium and high quality respectively [32]. Further, we also conducted a subgroup and sensitivity analysis to check potential source bias among the included studies. The types of primary headaches assessed, the country study conducted, and study design and the gender of study participants (male or female) were used as a moderator to assess subgroup and sensitivity analysis. The funnel plot and Egger's regression tests were used to assess potential publication bias [33].

\section{Results}

\section{Identification of studies}

The electronic database along with additional manual reference searches resulted in a total of 3295 research articles. Of these, 104 articles were retrieved for further screening and 87 articles were excluded, 17 research articles were included in the final meta-analysis (see Fig. 1).

\section{Characteristics of included studies}

A total of seventeen studies conducted both in developed and developing countries including 5564 study participants were included in this meta-analysis. The studies included in this systematic review were published between 2004 and 2019 and the sample size ranging between 86 in Turkey and 1109 in China. Of 17 studies included the final meta-analysis, one from the USA [34], one from India [35], three from Iran [36-38], one from

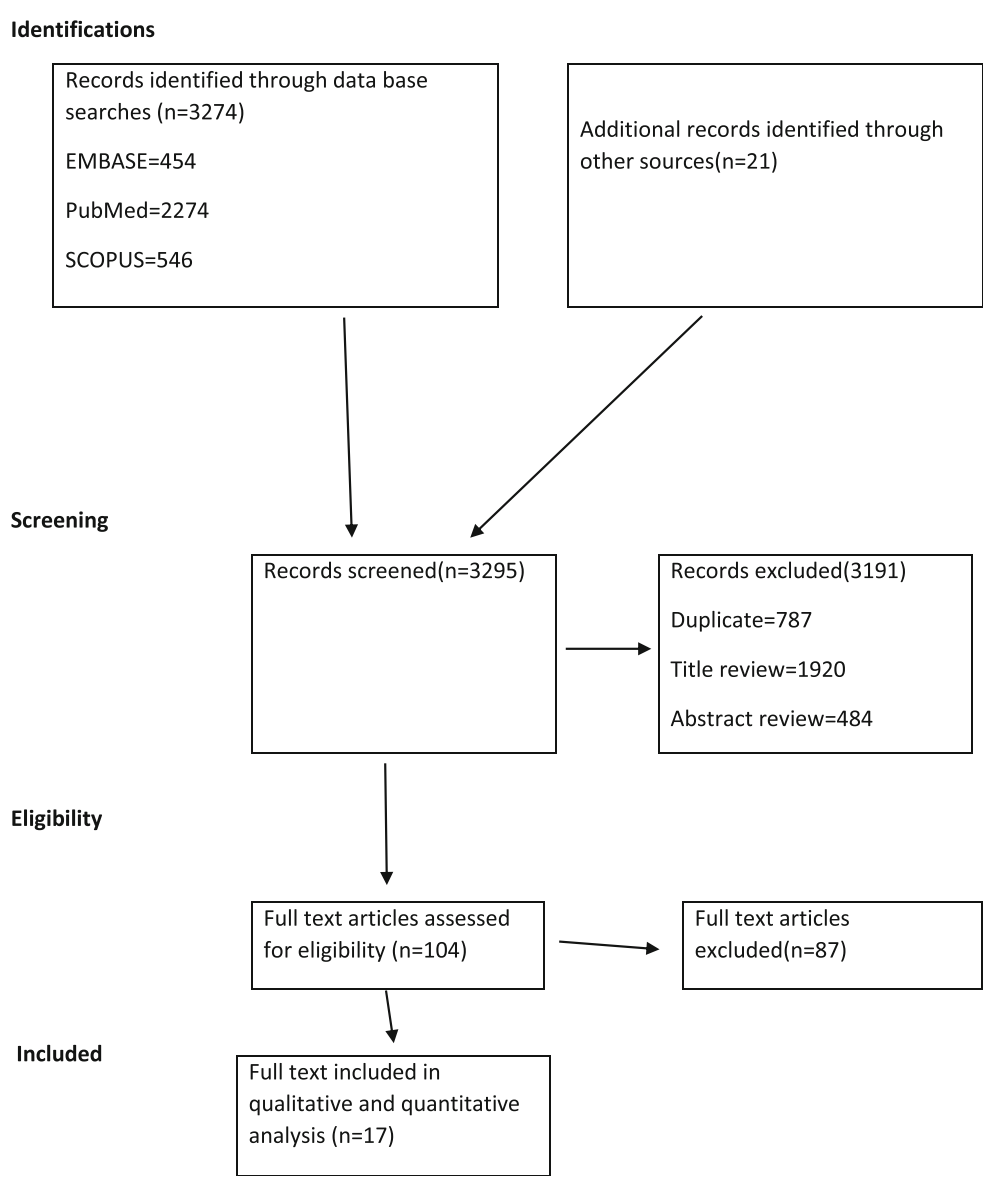

Fig. 1 PRISMA flowchart of review search 
Japan [26], one from Taiwan [35], one from Italy [36], three from China [25, 39, 40], one from Turkey [41], one from Lithuania [42], one from Montenegro [43], one from Bangladesh [44] and two from Egypt [45, 46]. Regarding types of headaches assessed among patients with epilepsy, nine studies assessed tension-type headache, fifteen studies assessed migraine with aura, three studies assessed migraine without aura, and seven studies assessed both Ictal headache $(\mathrm{IH})$ and Postictal headache (PIH). The studies included in the review used Migraine Screening -Questionnaire (MSQ), the International Classification of Headache Disorders 2nd and 3rd edition (ICHD-2, 3), the Headache-Attributed Lost Time (HALT) and the six-item Headache Impact Test (HIT-6) to assess primary headaches among patients with epilepsy (See Table 1).

\section{Quality of included studies}

The Newcastle Ottawa Scale (NOS) was used to check the quality of the included studies. Of 17 studies included in the review, 14 studies were of high quality (NOS score $>8$ ), 2 studies were moderate quality (NOS score between 6 and 7) and 1 study was low-quality studies (NOS score <5) (See Additional file 1).
The prevalence of headaches among patients living with epilepsy (meta-analysis)

The pooled prevalence estimate of headache among patients with epilepsy was $48.4 \%$ (95\% CI; 36.6-61.2). We found an apparent heterogeneity among included studies in this meta-analysis $\left(I^{2}=98.458 \% ; p<0.001\right)$ (See Fig. 2).

\section{Subgroup and sensitive analysis}

The available epidemiologic evidence was diverse by the types of headaches present in patients with epilepsy, the country in which a study conducted, the methodological design and the gender of study participants (male or female).

The pooled prevalence of headaches among patients with epilepsy differed when types of headaches differ. Thus, the pooled prevalence of Inter Ictal headache (IIH) (42.2\%) and Postictal headache (PIH) (43.1\%) among patients with epilepsy were higher when compared to tension-type headache (TTH) (26.2\%) (See Fig. 3), migraine with aura (26.0\%) (See Fig. 4) and migraine without aura (10.4\%).

The pooled prevalence of primary headaches among patients living with epilepsy did not differ in the

Table 1 Characteristics of the included studies on prevalence of headache among patients with epilepsy

\begin{tabular}{|c|c|c|c|c|c|c|c|c|c|c|c|c|}
\hline \multirow[t]{2}{*}{ First author, date } & \multirow[t]{2}{*}{ Country } & \multirow[t]{2}{*}{$\begin{array}{l}\text { Sample } \\
\text { size }\end{array}$} & \multirow[t]{2}{*}{ Study design } & \multirow{2}{*}{$\begin{array}{l}\text { Data } \\
\text { collection } \\
\text { tool }\end{array}$} & \multicolumn{2}{|c|}{$\begin{array}{l}\text { Prevalence } \\
(\%)\end{array}$} & \multirow[t]{2}{*}{$\begin{array}{l}\text { Prevalence of any } \\
\text { headache (\%) }\end{array}$} & \multicolumn{5}{|c|}{ Prevalence (\%) } \\
\hline & & & & & Male & $\overline{\text { Female }}$ & & $\overline{\mathrm{MA}}$ & $\mathrm{MOA}$ & $\mathrm{TTH}$ & $\mathrm{IH}$ & $\mathrm{PIH}$ \\
\hline Erin K, 2017 [34] & USA & 160 & Cross-sectional & Self-report & $\mathrm{NA}$ & NA & 40.00 & NA & & & & \\
\hline Singla et al., 2019 [35] & India & 123 & Cohort & Self-report & NA & NA & 47.10 & 21.10 & & 26.00 & & \\
\hline Sayena J et al., 2015 [36] & Iran & 150 & Cross-sectional & MSQ & NA & NA & 32.60 & 15.30 & 17.30 & & & \\
\hline Ashjazadeh N, 2015 [37] & Iran & 100 & Cross-sectional & ICHD-II & 48 & 52 & 54.00 & 15.00 & & 39.00 & 42.53 & 31.48 \\
\hline $\begin{array}{l}\text { Fattahzadeh AG et al., } \\
2017 \text { [38] }\end{array}$ & Iran & 900 & Cross-sectional & HIS & NA & NA & 85.20 & 27.90 & & 48.20 & & \\
\hline Ito M et al., 2004 [26] & Japan & 364 & Cross-sectional & $|\mathrm{CHD}-|||$ & NA & NA & 40.40 & 26.00 & & & 50.00 & 40.40 \\
\hline Inn-Chi L., 2018 [47] & Taiwan & 476 & Cross-sectional & $|C H D-|||$ & NA & NA & 9.70 & 9.70 & & & & \\
\hline Mainieri et al., 2015 [39] & Italy & 388 & Cross-sectional & $|\mathrm{CHD}-| \mid$ & NA & NA & 53.90 & 26.30 & & 19.10 & 48.50 & 19.10 \\
\hline Zhang et al., 2018 [37] & China & 339 & Cross-sectional & $|C H D-|||$ & 17 & 29 & 23.00 & 23.00 & & & & \\
\hline $\begin{array}{l}\text { Gökhan Ö et al., } \\
2010 \text { [41] }\end{array}$ & Turkey & 86 & Cohort & Self-report & NA & NA & 47.60 & 13.90 & 12.80 & 16.30 & & \\
\hline $\begin{array}{l}\text { Mameniškiene R et al., } \\
2016 \text { [42] }\end{array}$ & Lithuania & 289 & Cross-sectional & HALT & 42 & 62 & 83.20 & 31.70 & & 39.00 & 77.90 & \\
\hline Wang et al., 2014 [25] & China & 1109 & Cross-sectional & $|\mathrm{CHD}-| \mid$ & 57 & 64 & 60.10 & 60.20 & & 30.30 & 11.70 & 34.10 \\
\hline Slavica V. et al., 2012 [43] & Montenegro & 259 & Cross-sectional & $\mid \mathrm{CDH} \|$ & 20 & 85 & 48.00 & 15.44 & & & & 28.00 \\
\hline Shamim R..,2018 [44] & Bangladesh & 376 & Cross-sectional & NA & NA & NA & 80.60 & NA & & & & 80.60 \\
\hline Kwan P et al., 2008 [38] & China & 227 & Cohort & HIT-6 & 68 & NA & 22.00 & 4.80 & 3.10 & 7.00 & 19.80 & \\
\hline Yosria AHA. et al., 2017 [41] & Egypt & 118 & Case control & $|C H D-|||$ & 31 & 69 & 24.60 & 79.30 & & & & \\
\hline Sayed MA et al, 2019 [42] & Egypt & 100 & Cross-sectional & $|C H D-|||$ & 27 & 73 & 78.00 & 70.60 & & 25.58 & 50.00 & 66.50 \\
\hline
\end{tabular}

Foot notes: MSQ Migraine Screening Questionnaire, ICHD-II The International Classification of Headache Disorders 2nd edition, ICHD-3 The International Classification of Headache Disorders 3rd edition, HALT The Headache-Attributed Lost Time, HIT-6 The six-item Headache Impact Test, IHS International Headache Society, MA migraine with aura, MOA Migraine without aura, $T H H$ Tension type headache, PIH Post ictal headache, IIH Inter Ictal headache 


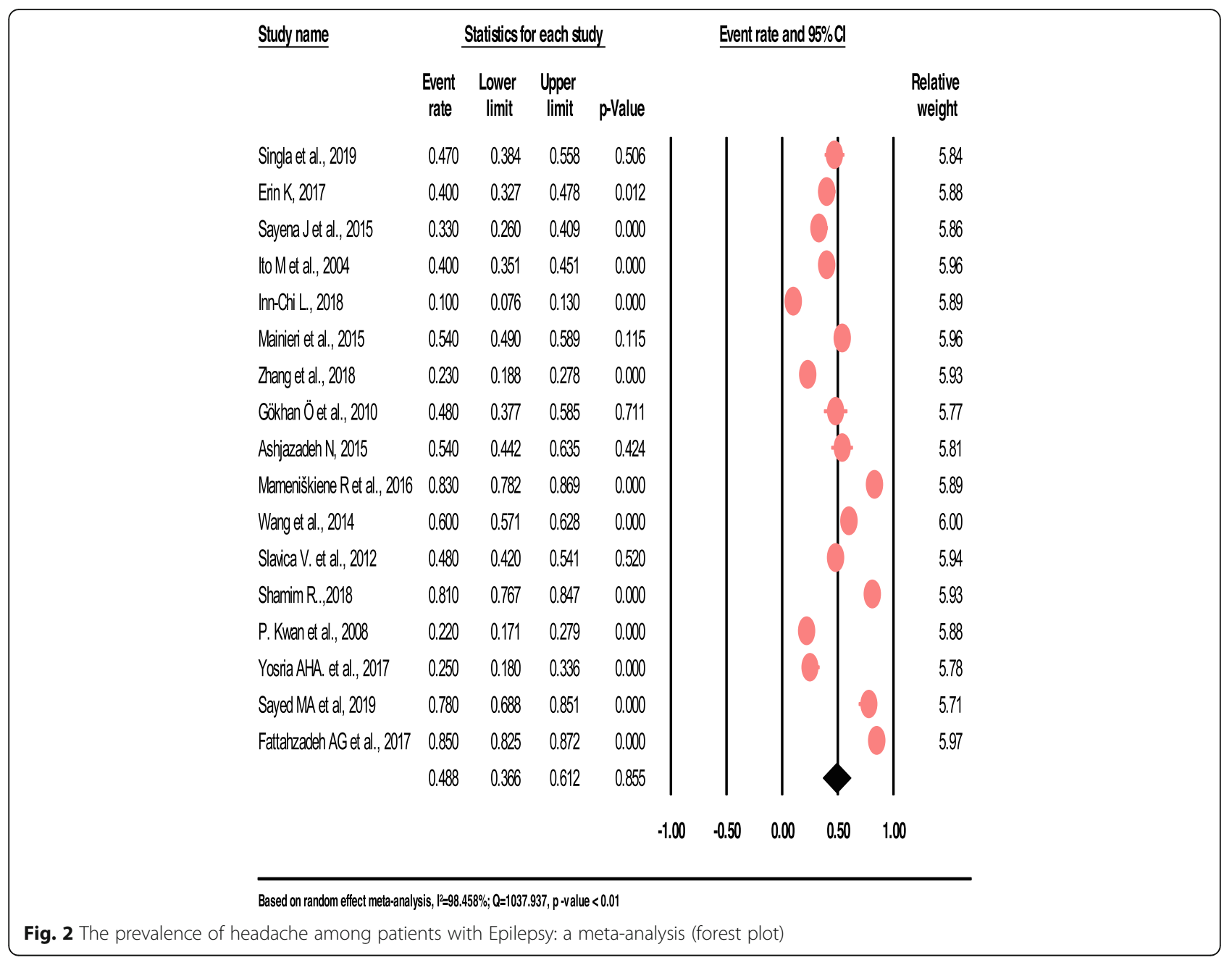

subgroup analysis of developing and developed countries as a moderator. For example, the pooled prevalence of headaches was $50.6 \%$ (95\%CI $35.9-65.3)$ and $49.5 \%$ (95\%CI 38.1-60.9) for developed and developing countries respectively. The variation between the studies was statistically significant $(P<0.001)$.

We also performed a subgroup analysis using the methodological design studies conducted as a moderator. The prevalence of primary headaches was higher in the studies that used a cross-sectional study design (53.4\%) when compared to the studies that used cohort (37.9\%) and case-control study (25.0\%) designs.

We further conducted a subgroup analysis using the gender of the study participants as a moderator. The pooled prevalence of headaches among patients with epilepsy was considerably higher among females (63.0\%) when compared to males (33.3\%). The heterogeneity was significant for both studies that assessed the prevalence of headaches in females $\left(I^{2}=96.958 \%, p<0.001\right)$ and $\left(I^{2}=97.451 \%, p<0.001\right)$ (See Table 2).
Moreover, we conducted a leave-one-out sensitivity analysis to further explore the source heterogeneity. The pooled prevalence of headaches among patients with epilepsy was ranging from $46.0 \%(35.0-57.4)$ to $52.2 \%$ (40.8-63.4) in the leave-one-out sensitivity analysis (See Table 3).

\section{Publication bias}

For the overall meta-analysis of the prevalence of headache among patients with epilepsy, both funnel plot and Egger's regression tests revealed no evidence of potential publication bias $(\mathrm{B}=-6.59, \mathrm{SE}=5.23, P=0.23)$ (See Fig. 5).

\section{Discussion}

To our knowledge, this is the first systematic review and meta-analysis that assessed the prevalence of headaches among patients with epilepsy globally. In this review, the pooled prevalence of headaches among patients with epilepsy was $48.4 \%$. The available epidemiologic evidence 


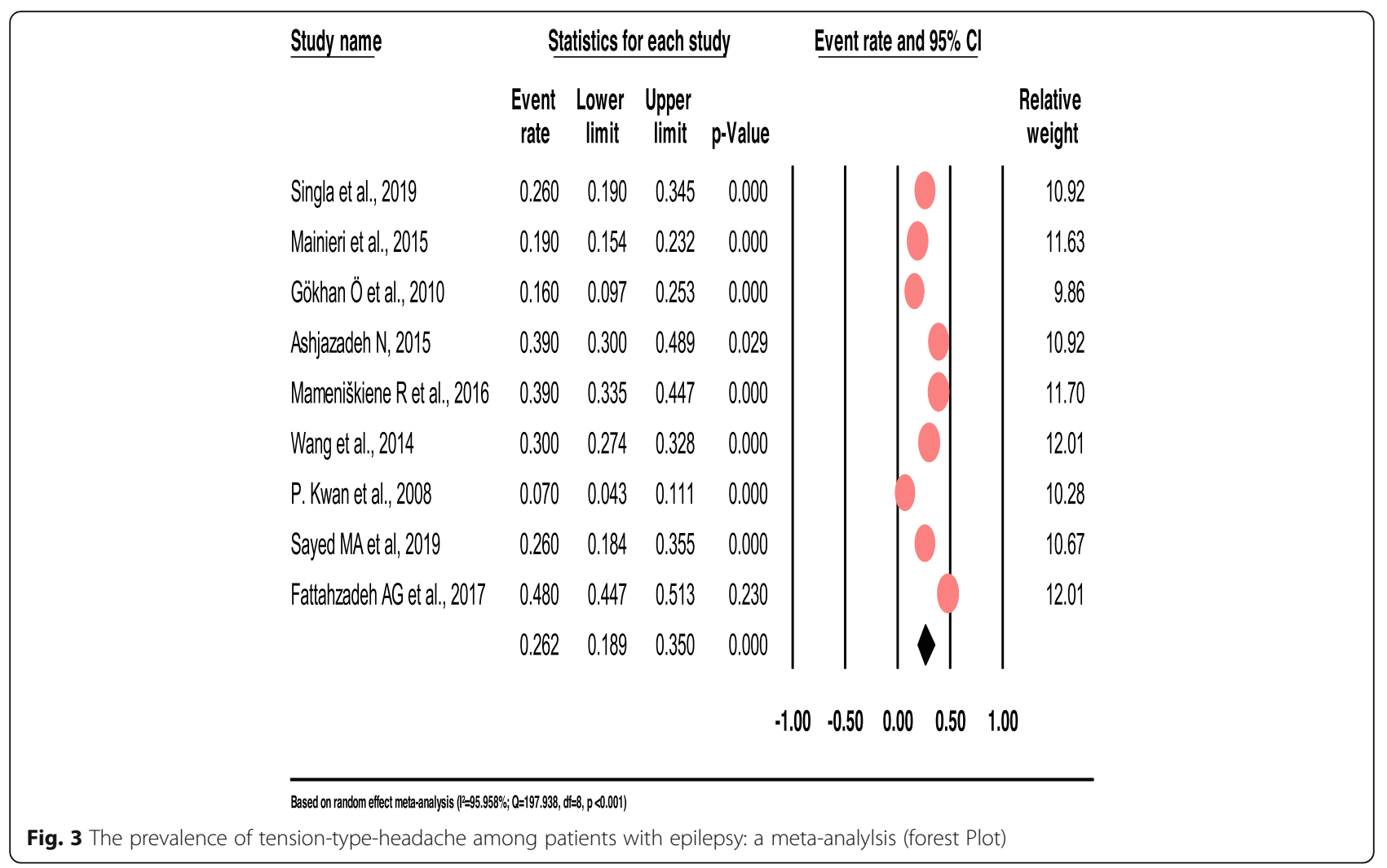

was diverse by the types of headaches present in patients with epilepsy, the country in which a study conducted, the methodological design and the gender of study participants (male or female). Further, the majority of included studies were of high methodological quality.

The pooled prevalence estimate of headache among patients with epilepsy in the current systematic review and meta-analysis $(48.4 \%)$ was in line with the World Health Organization (WHO) report of 2016 which estimated the prevalence of headache disorders among adults was 50\% [48]. However, the pooled prevalence of headache among patients with epilepsy was higher than the reported prevalence of headache in the general population. For example, the studies conducted to assess the prevalence of primary headache disorders in a geriatric population (age $>60$ years) in a rural area of Northern China reported 10.3\% [49]. This study finding was supported by a community-based cross-sectional study conducted to assess the burden of primary headache disorders among Kuwaiti children and adolescents and revealed $19.4 \%$ [50]. The finding from a study conducted to assess the prevalence of headache among medical students in Saudi Arabia also reported of 41.66\% [51]. Further, a study that described the clinical characteristics of primary headaches occurring in a group of HIV-infected individuals and reported 38\% [52]. The discrepancy in the prevalence of headache may be due to the difference in the study population, setting and, also primary headaches such as migraines share some common signs and symptoms with epilepsy, therefore, this may increase the prevalence of headaches among patients with epilepsy. In addition, there are numerous ways in which common genetic factors such as SCN1A mutations that predispose persons to the development of headaches and epilepsy [27, 53] and the corresponding mutations may result in higher prevalence of headaches among patients with epilepsy [54]. A study conducted to assess the contribution of a shared genetic susceptibility to migraine and epilepsy reported that the prevalence of a history of migraine was significantly increased in participants with affected first degree relatives [55]. Further, shared environmental factors e.g. head injury, may result in brain hyper-excitability [56], and these may play a great role in the variation of prevalence of headache among patients with epilepsy when compared to the general population.

In this review, the pooled prevalence of migraine and tension-type headache in patients with epilepsy was $26.0 \%$ and $26.2 \%$ respectively. The pooled estimated prevalence of migraine and tension-type headaches were higher than pre-Ictal headaches reported by different studies [25, 39]. Further, the pooled prevalence of migraine was higher than the prevalence of migraine and tension-type headache in the general population. For example, a research article published simultaneously by 


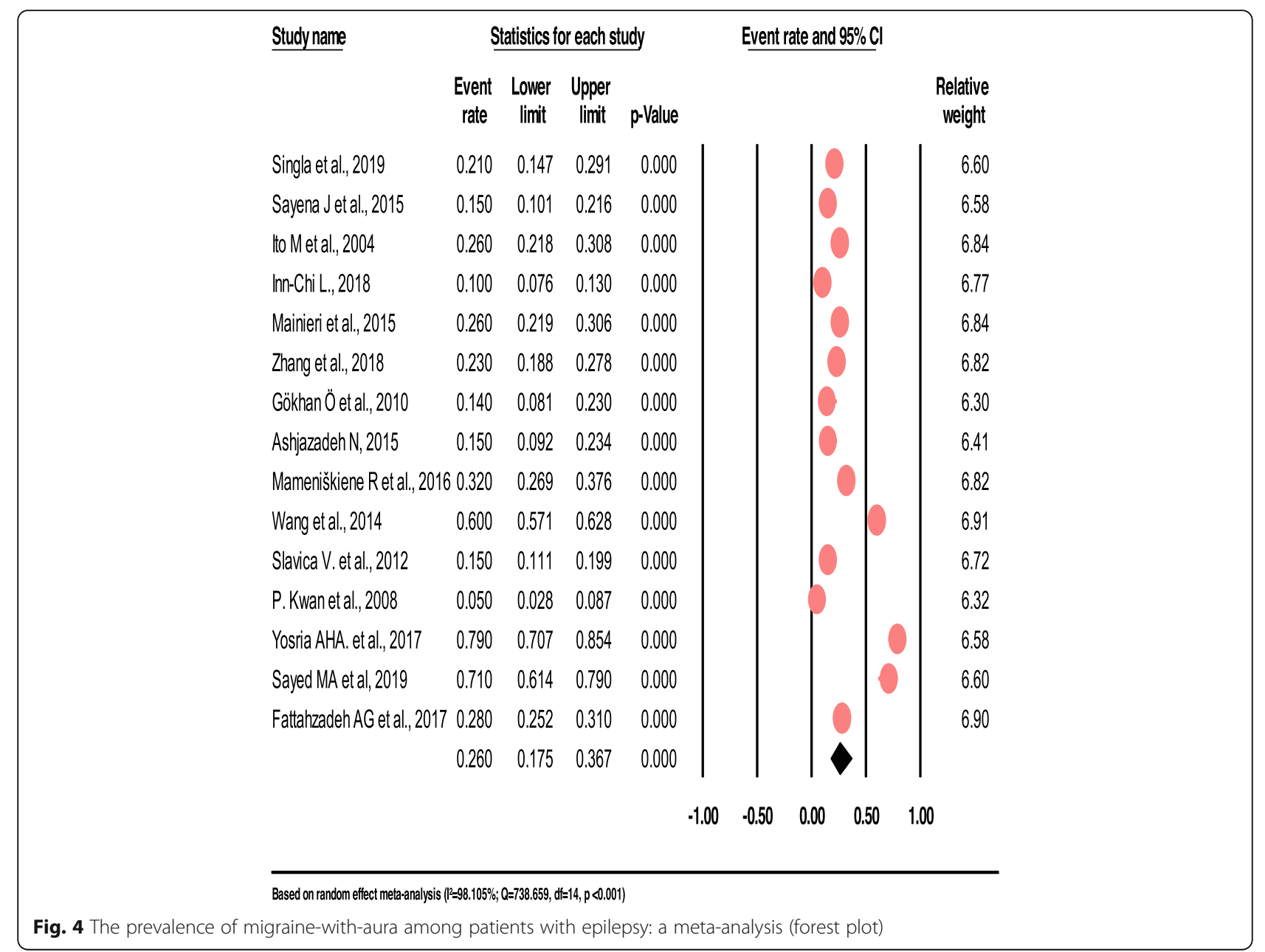

Table $\mathbf{2}$ Subgroup and sensitivity analysis for the prevalence of headaches among patients with epilepsy

\begin{tabular}{|c|c|c|c|c|c|c|}
\hline \multirow[t]{2}{*}{ Subgroups } & \multirow{2}{*}{$\begin{array}{l}\text { No. of } \\
\text { studies }\end{array}$} & \multirow{2}{*}{$\begin{array}{l}\text { Prevalence } \\
\text { (\%) }\end{array}$} & \multirow[t]{2}{*}{$95 \% \mathrm{Cl}$} & \multicolumn{3}{|c|}{ Heterogeneity within the study $\left(I^{2}, \mathrm{Q}\right.$ and $p$-value) } \\
\hline & & & & Q-value & $I^{2}(\%)$ & $P$-value \\
\hline \multicolumn{7}{|l|}{ Types of Headache } \\
\hline Tension type headache (TTH) & 9 & 26.2 & $18.9-35.0$ & 197.938 & 95.958 & \multirow[t]{5}{*}{$<0.01$} \\
\hline Migraine with aura & 15 & 26.0 & $17.5-36.7$ & 738.659 & 98.105 & \\
\hline Migraine without aura & 3 & 10.4 & $5.20-19.7$ & 11.064 & 81.924 & \\
\hline Ictal headache $(I H)$ & 7 & 42.2 & $26.8-59.2$ & 523.957 & 98.664 & \\
\hline Post ictal headache (PIH) & 7 & 43.1 & $30.9-56.3$ & 348.352 & 97.991 & \\
\hline \multicolumn{7}{|l|}{ Countries } \\
\hline Developed & 6 & 50.6 & $35.9-65.3$ & 142.400 & 96.489 & \multirow[t]{2}{*}{$<0.01$} \\
\hline Developing & 11 & 49.5 & $38.1-60.9$ & 885.368 & 98.871 & \\
\hline \multicolumn{7}{|l|}{ Study design } \\
\hline Cross-sectional & 13 & 53.4 & $39.2-67.0$ & 909.646 & 98.681 & \multirow[t]{3}{*}{$<0.01$} \\
\hline Cohort & 3 & 37.9 & $21.3-57.8$ & 30.119 & 93.360 & \\
\hline Case-control & 1 & 25.0 & $18.0-33.6$ & 0.000 & 0.000 & \\
\hline \multicolumn{7}{|l|}{ Gender } \\
\hline Male & 7 & 33.3 & $21.1-48.3$ & 235.349 & 97.451 & \multirow[t]{2}{*}{$<0.01$} \\
\hline Female & 7 & 63.0 & $49.1-75.1$ & 197.232 & 96.958 & \\
\hline
\end{tabular}


Table 3 Leave-one-out-sensitivity analysis of prevalence of headache among patients: prevalence and 95\% confidence

\begin{tabular}{lll}
\hline Study excluded & Prevalence (\%) & $95 \% \mathrm{Cl}$ \\
\hline Singla et al., 2019 & 48.9 & $36.2-61.8$ \\
Erin K, 2017 & 49.4 & $36.6-62.3$ \\
Sayena J et al., 2015 & 49.9 & $37.2-62.6$ \\
Ito M et al., 2004 & 49.4 & $36.4-62.5$ \\
Inn-Chi L., 2018 & 52.2 & $40.8-63.4$ \\
Mainieri et al., 2015 & 48.5 & $35.3-61.9$ \\
Zhang et al., 2018 & 50.7 & $38.3-62.9$ \\
Gökhan Ö et al., 2010 & 48.9 & $36.2-61.7$ \\
Ashjazadeh N, 2015 & 48.5 & $35.8-61.4$ \\
Mameniškiene R et al., 2016 & 46.3 & $34.2-58.9$ \\
Wang et al., 2014 & 48.1 & $34.2-62.4$ \\
Slavica V. et al., 2012 & 48.9 & $35.9-62.0$ \\
Shamim R..,2018 & 46.5 & $34-3-59.1$ \\
P. Kwan et al., 2008 & 50.7 & $38.3-63.1$ \\
Yosria AHA. et al., 2017 & 50.4 & $37.9-63.0$ \\
Sayed MA et al., 2019 & 46.9 & $34.5-59.6$ \\
Fattahzadeh AG et al., 2017 & 46.0 & $35.0-57.4$ \\
\hline
\end{tabular}

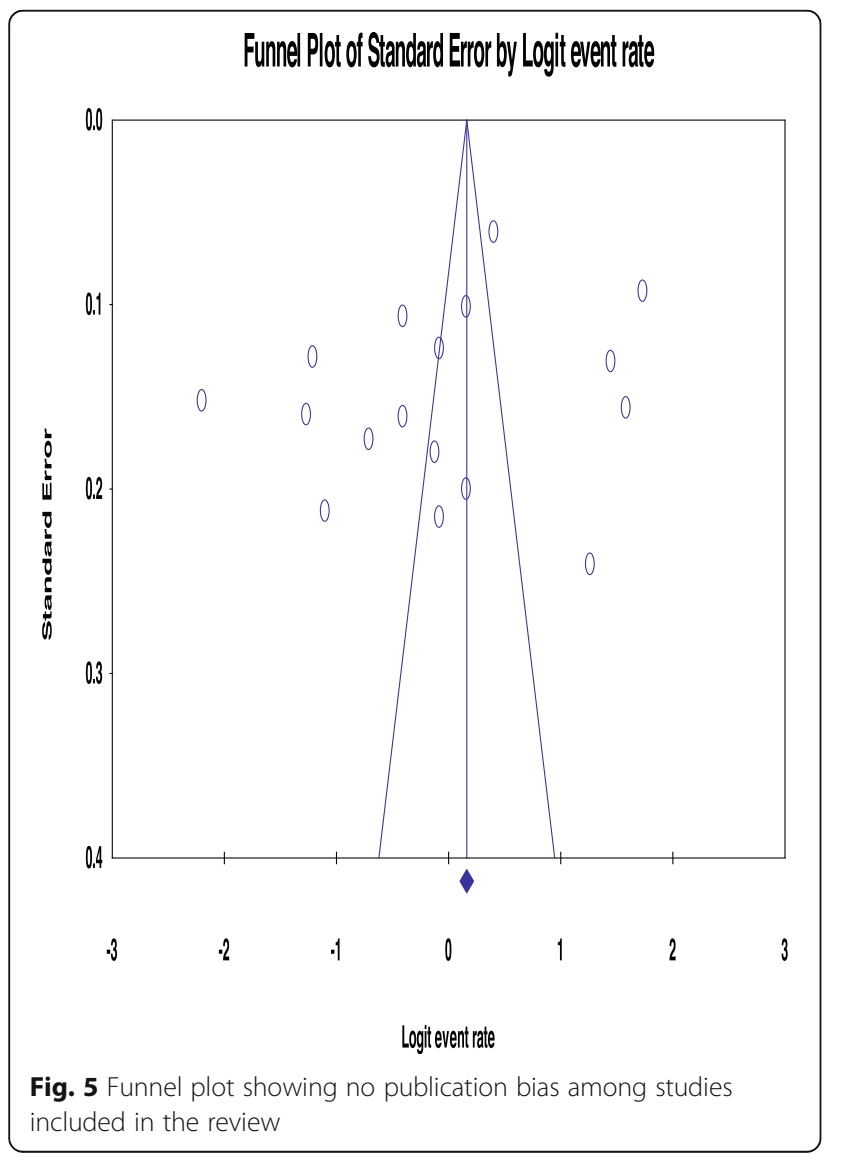

Cephalalgia Headache and the Journal of Headache and Pain in 2013 showed that the global prevalence of migraine in the general population was $14.7 \%$ [57, 58]. Also, a systematic review conducted in 2010 to assess the prevalence of chronic migraines reported $0-5.1 \%$ in the general population [59]. This may be due to the comorbidity of migraine and epilepsy in which the two disorders experience common symptoms, risk factors, and drug therapy [25]. Findings from previous studies support the hypothesis of cortical excitability as a plausible mechanism underlying their pathology [60]. Further, there is corroboration from the scientific study of the nervous system that cortical spreading depression and an epileptic focus may exacerbate each other [61].

In our subgroup analysis, the pooled prevalence of headaches among patients with epilepsy was considerably higher among females (63.0\%) when compared to males (33.3\%). Data from different epidemiologic studies reported that female manifests high prevalence of migraine [62]. The same study also showed that female experiences more frequent, longer-lasting and more intense attacks than male [61,62]. Further, scientific evidence has shown that primary headaches such as migraines are associated with sex hormones [61]. Finding from this study showed that sex hormones in females affect cells around the trigeminal nerve as well as connected blood vessels in the head. The estrogens, which are hormones that are responsible for reproductive and sexual development in females, at their highest levels in the females of childbearing age are particularly important for sensitizing these cells to migraine triggers [63]. Furthermore, a study included a total of 2082 study participants to investigate the effect of gender on the headache manifestations in migraine patients and reported that the headache intensity in males changed in an agedependent manner and these variations were not seen in males [64].

The pooled prevalence of primary headaches among patients living with epilepsy did not differ in the subgroup analysis of developing and developed countries. For example, the pooled prevalence of primary headaches was $50.6 \%$ and $49.5 \%$ for developed and developing countries respectively. These may indicate the risk factors of headache among patients with epilepsy are common irrespective of the countries' socio-economic status and suggesting some common biological factors are explaining the co-occurrence.

\section{Strength and limitations}

This systematic review and meta-analysis has the following strengths; we used a predefined search strategy and two independent reviewers conducted data extraction and quality appraisal to minimize reviewer bias, conducted sensitivity and subgroup analysis using types 
of headaches, the countries the study based and the gender of the participants as a moderator. Nevertheless, this systematic review has the following limitations. We got a small number of articles in the subgroup analysis which could decrease the accuracy of the estimate. We did not analyze the data on children due to lack of sufficient literature. Furthermore, some studies included in the review did not use standardized and validated data measurement tools. These may overestimate the prevalence of headache in the studies that used a nonstandardized data collection tool. Moreover, the review included studies published in the English language only. This may under- or over-estimate the pooled prevalence of headache among patients with epilepsy.

\section{Conclusion}

The pooled prevalence estimates of headache among patients with epilepsy was considerably high when compared to the general population. The pooled prevalence of Inter Ictal headache (IIH) and Postictal headache (PIH) were higher when compared to tension-type headache $(\mathrm{TTH})$, migraine with aura and migraine without aura. The pooled prevalence of headache was similar for developed and developing countries. The pooled prevalence of headache among patients with epilepsy was considerably higher among females when compared to males. Screening and appropriate management of headaches among patients with epilepsy are warranted.

\section{Supplementary information}

Supplementary information accompanies this paper at https://doi.org/10. 1186/s10194-020-1074-0.

Additional file 1. The quality of studies included in systematic review and meta-analysis.

\section{Abbreviations \\ HALT: The Headache-Attributed Lost Time; HIT-6: The six-item Headache Im- pact Test; ICHD-III: The International Classification of Headache Disorders 3rd edition; IHS: International Headache Society; IIH: Inter Ictal headache; MA: Migraine with aura; MOA: Migraine without aura; MSQ: Migraine Screening Questionnaire; PIH: Post ictal headache; TTH: Tension type headache}

\section{Acknowledgements}

No acknowledgements at this stage.

\section{Authors' contributions}

BD performed the database search, data extraction, quality assessment, analysis, and write-up and drafted the manuscript. MA performed the database search, data extraction and write-up. AT was involved in database search and write-up. All authors read and approved the final manuscript.

\section{Funding}

The authors declare that there is no funding.
Ethics approval and consent to participate

N/A.

\section{Consent for publication}

N/A.

\section{Competing interests}

The authors declare that there is no competing interests.

Received: 9 December 2019 Accepted: 5 January 2020

Published online: 10 January 2020

\section{References}

1. Thakur KT, Albanese E, Giannakopoulos P, Jette N, Linde M, Prince MJ, et al. Neurological Disorders. 2016

2. World Health Organazation (2019), keys facts on epilepsy, https://www.who. int/news-room/factsheets/detail/epilepsy

3. Falco-Walter J, Scheffer I, Fisher R (2018) The new definition and classification of seizures and epilepsy. Epilepsy Res 139:73-79

4. Fisher RS, Acevedo C, Arzimanoglou A, Bogacz A, Cross JH, Elger CE et al (2014) ILAE official report: a practical clinical definition of epilepsy. Epilepsia. 55(4):475-482

5. Nunes V, Sawyer L, Neilson J, Sarri G, Cross J (2012) Diagnosis and management of the epilepsies in adults and children: summary of updated NICE guidance. BMJ. 344:e281

6. Singh A, Trevick S (2016) The epidemiology of global epilepsy. Neurol Clin 34:837-847

7. De Boer H, Mula M, Sander J (2008) The global burden and stigma of epilepsy. Epilepsy Behav 12:540-546

8. Fiest KM, Sauro KM, Wiebe S, Patten SB, Kwon CS, Dykeman J, Jetté N (2017) Prevalence and incidence of epilepsy: a systematic review and meta-analysis of international studies. Neurol 88(3):296-303

9. Petitmengin C (2006) Describing One's subjective experience in the second person: an interview method for the science of consciousness. Phenomenol Cogn Sci 5:229-269

10. Borsook D, Dodick DW (2015) Taking the headache out of migraine. Neurology Clinical practice 5(4):317-325

11. Headache disorders Fact sheet $N^{\circ} 277 "$. October 2012. Archived from the original on 16 February 2016. Retrieved 15 February 2016.https://en. wikipedia.org/wiki/Headache

12. Clinch C (2011) Chapter 28. Evaluation \& Management of headache CURRENT Diagnosis \& Treatment in family medicine. In: South-Paul JE, Matheny SC, Lewis EL (eds) Lange Current Series, Third edn. McGraw-Hill. isbn: 9780071624367

13. Detsky ME, McDonald DR, Baerlocher MO, Tomlinson GA, McCrory DC, Booth CM (September 2006). "Does this patient with headache have a migraine or need neuroimaging?" JAMA. 296 (10): 1274-1283. doi:https:// doi.org/10.1001/jama.296.10.1274. PMID 16968852

14. Bellosta-Diago E, Velazquez-Benito A, Viloria-Alebesque A, Iniguez-Martinez C, Santos-Lasaosa S (2016) A study of sexual function in migraine and cluster headache. Rev Neurol 62(11):487-492

15. Jin H, Ding Z, Lian S, Zhao Y, He S, Zhou L et al (2019) Prevalence and Risk Factors of White Matter Lesions in Tibetan Patients Without Acute Stroke. Stroke 51(1):149-153. https://doi.org/10.1161/STROKEAHA.119.027115

16. Kinard Kl, Smith AG, Singleton JR, Lessard MK, Katz BJ, Warner JE et al (2015) Chronic migraine is associated with reduced corneal nerve fiber density and symptoms of dry eye. Headache. 55(4):543-549

17. Prontera P, Sarchielli P, Caproni S, Bedetti C, Cupini LM, Calabresi P et al (2018) Epilepsy in hemiplegic migraine: genetic mutations and clinical implications. Cephalalgia 38(2):361-373

18. Kim DW, Lee SK (2017) Headache and epilepsy. J Epilepsy Res 7(1):7-15

19. Sutherland $H G$, Albury $C L$, Griffiths LR (2019) Advances in genetics of migraine. J Headache Pain 20:72. https://doi.org/10.1186/s10194-019-1017-9

20. Belcastro V, Striano P, Parisi P (2012) "Ictal epileptic headache": beyond the epidemiological evidence. Epilepsy Behav 25:9-10

21. Dedei Daryan M, Guveli BT (2018) Prevalence and clinical characteristics of headache in juvenile myoclonic epilepsy: experience from a tertiary epilepsy center. 39(3):519-525

22. Kingston WS, Schwedt TJ (2017) The relationship between headaches with epileptic and non-epileptic seizures: a narrative review. Curr Pain Headache Rep 21(3):17 
23. Nesterovsky YE, Zavadenko NN (2018) Comorbidity of migraine and epilepsy in childhood. Zh Nevrol Psikhiatr Im S S Korsakova 118(4):100-106

24. Mutlu A (2018) Association between epilepsy and headache. Neurol Sci 39(12):2129-2134

25. Wang XQ, Lang SY, He MW, Zhang X, Zhu F, Dai W, Yu SY (2014) High prevalence of headaches in patients with epilepsy. J Headache Pain 15(1): 70. https://doi.org/10.1186/1129-2377-15-70

26. Ito M, Nakamura F, Honma H, Takeda Y, Kobayashi R, Miyamoto T et al (2000) Clinical factors associated with post-ictal headache in patients with epilepsy. Acta Neurol Scand 102(2):129-131

27. Keezer MR, Sisodiya SM, Sander JW (2016) Comorbidities of epilepsy: current concepts and future perspectives. Lancet Neurol 15(1):106-115

28. Reviews UoYCf (2009) Dissemination. Systematic reviews: CRD's guidance for undertaking reviews in health care. University of York, Centre for Reviews \& Dissemination

29. Stang A (2010) Critical evaluation of the Newcastle-Ottawa scale for the assessment of the quality of nonrandomized studies in meta-analyses. Eur J Epidemiol 25(9):6035

30. Modesti PA, Reboldi G, Cappuccio FP, Agyemang C, Remuzzi G, Rapi S et al (2016) Panethnic differences in blood pressure in Europe: a systematic review and meta-analysis. PLoS One 11(1):e0147601

31. Borenstein M, Hedges LV, Higgins J, Rothstein HR (2010) A basic introduction to fixed-effect and random-effects models for meta-analysis. Res Synth Methods 1(2):97-111

32. Higgins JP, Thompson SG, Deeks JJ, Altman DG (2003) Measuring inconsistency in meta-analyses. BMJ 327(7414):557

33. Sterne JAC, Gavaghan D, Egger M (2000) Publication and related bias in meta-analysis: Power of statistical tests and prevalence in the literature. $J$ Clin Epidemiol 53(11):1119-1129

34. Saito EK, Mehta B, Wang F, Nakamoto B, McMurtray AM (2017) Headaches more common among epilepsy sufferers with Neurocysticercosis than other structural brain lesions. Hawai'i J Med Public Health 76(6):152-155

35. Singla M, Mayyer A, Singh G, Sidhu J, Aggarwal S (2017) To study the prevalence of headache in patients with epilepsy. J Neurol Sci 381:689

36. Jabbehdari S, Hesami O, Chavoshnejad M (2015) Prevalence of migraine headache in epileptic patients. Acta Medica Iranica 53(6):373-375

37. Nahid A, Hakimeh J (2015) the prevalence of migraine and tension type headaches among epileptic patients. Caspian J Neurol Sci 1(3):41-46

38. Fattahzadeh-Ardalani G, Ahari SS, Amani F, Moghaddamnia V (2017 May) prevalence of migraine and tension headaches and related factors, 2014. Int J Res Med Sci 5(5):2016-2020

39. Mainieri G, Cevoli S, Giannini G, Zummo L, Leta C, Broli M et al (2015) Headache in epilepsy: prevalence and clinical features. J Headache Pain. 16: 556

40. Zhang L, Zhu X, Qiu X et al (2018) Relationship between right-to-left shunt and migraine in patients with epilepsy: a single-Centre, cross-sectional study in China. BMJ Open 8:e024144

41. Özer G, Ünal Y, Kutlu G, Gömceli Y, Inan L (2018) Prevalence of Interictal headache in patients with epilepsy. Epilepsi 24(2):51-54

42. Mameniskiene R, Karmonaite I, Zagorskis R (2016) The burden of headache in people with epilepsy. Seizure. 41:120-126

43. Vujisi S, Radulovi L, Vodopi S (2012) comorbidity of epilepsy and migraines epidemiological and clinical aspects. SANAMED 7(2):79-84

44. Rashid S, Alam MM (2018) Headache Associated with Epileptic Seizures: Epidemiology and Clinical Characteristics. IOSR J Dental Med Sci 17(9 9):17-24

45. Yosria Abd Al Hameed Altaweel, Amal Salah El-Din Mohamed El-Motayam, Khaled Aly El-Sharkawy, and Mohammed Hanafy Aly Ghonemy, "Prevalence of Comorbidity of Migraine and Atopic Diseases among Patients with Idiopathic Epilepsy in Zagazig University Hospitals, Int J Clin Exp Neurol, 5, no. 1 (2017): 18-27. doi: https://doi.org/10.12691/ijcen-5-1-5

46. Sayed M, Ibrahim H, Bekhit A, Thabit M, Abdelmomen M (2019) Clinical characteristics of headache in Egyptian patients with idiopathic epilepsy. J Behav Brain Sci 9:144-153

47. Lee $\mid-C$, Chen Y-J (2018) Incidence and characteristics of headaches in a retrospective cohort of Taiwanese children with focal epilepsy. Neuropsychiatry (London) 8(2):727-732

48. World Health Organazation (WHO), Headache disorders, (2016) https://www. who.int/news-room/fact-sheets/detail/headache-disorders
49. Zhang Y, Shi Z, Hock D, Yue W, Liu S, Zhang Y et al (2016) Prevalence of primary headache disorders in a population aged 60 years and older in a rural area of northern China. J Headache Pain 17(1):83

50. Al-Hashel JY, Ahmed SF, Alroughani R (2019) Prevalence and Burden of Primary Headache Disorders in Kuwaiti Children and Adolescents: A Community Based Study. Front Neurol 10(793)

51. Almesned IS, Alqahtani NG, Alarifi JA, Alsaawy TN, Agha S, Alhumaid MA (2018) Prevalence of primary headache among medical students at king Saud bin Abdulaziz University for health sciences, Riyadh, Saudi Arabia. J Fam Med Prim Care 7(6):1193-1196. https://doi.org/10.4103/jfmpc.jfmpc_ 240_18

52. Mirsattari SM, Power C, Nath A (1999) Primary headaches in HIV-infected patients. Headache. 39(1):3-10

53. Brunklaus A, Ellis R, Reavey E, Forbes GH, Zuberi SM (2012) Prognostic clinical and demographic features in SCN1A mutation-positive Dravet syndrome. Brain 135:2329-2336

54. Ligthart L, Boomsma DI (2012) causes of comorbidity: pleiotropy or causality? Shared genetic and environmental influences on migraine and neuroticism. Twin Res Hum Genet 15:158-165

55. Winawer MR, Connors R (2013) Evidence for a shared genetic susceptibility to migraine and epilepsy. Epilepsia. 54(2):288-295

56. Rogawski MA Migraine and Epilepsy_-Shared Mechanisms within the Family of Episodic Disorders, asper's Basic Mechanisms of the Epilepsies [Internet], 4th edn https://www.ncbi.nlm.nih.gov/books/NBK98193/

57. Steiner TJ, Stovner LJ, Birbeck GL (2013) Migraine: the seventh disabler. J Headache Pain 14(1):1. https://doi.org/10.1186/1129-2377-14-1

58. Natoli, J., Manack, A., Dean, B., Butler, Q., Turkel, C., Stovner, L., \& Lipton, R. Global prevalence of chronic migraine: a systematic review. Cephalalgia, (2010) 30(5), 599-609. https://doi.org/https://doi.org/10.1111/j.1468-2982. 2009.01941.x

59. Vanmolkot KR, Kors EE, Hottenga JJ, Terwindt GM, Haan J, Hoefnagels WA Black DF, Sandkuijl LA, Frants RR, Ferrari MD, van den Maagdenberg AM (2003) Novel mutations in the Na+, $\mathrm{K}+-$ ATPase pump gene ATP1A2 associated with familial hemiplegic migraine and benign familial infantile convulsions. Ann Neurol 54:360-366

60. Eikermann-Haerter K, Negro A, Ayata C (2013) Spreading depression and the clinical correlates of migraine. Rev Neurosci 24:353-363

61. Artero-Morales M, González-Rodríguez S, Ferrer-Montiel A (2018) TRP Channels as Potential Targets for Sex-Related Differences in Migraine Pain. Front Mol Biosci 5(73)

62. Boardman HF, Thomas E, Croft PR, Millson DS (2003) Epidemiology of headache in an English district. Cephalalgia 23:129-137. https://doi.org/10. 1046/j.1468-2982.2003.00468.x

63. Bolay H, Ozge A, Saginc P, Orekici G, Uludüz D, Yalin O et al (2015) Gender influences headache characteristics with increasing age in migraine patients. Cephalalgia 35:792-800. https://doi.org/10.1177/0333102414559735

64. Kwan P, Man CB, Leung H, Yu E, Wong KS (2008) Headache in patients with epilepsy: a prospective incidence study. Epilepsia. 49(6):1099-1102

\section{Publisher's Note}

Springer Nature remains neutral with regard to jurisdictional claims in published maps and institutional affiliations.

Ready to submit your research? Choose BMC and benefit from:

- fast, convenient online submission

- thorough peer review by experienced researchers in your field

- rapid publication on acceptance

- support for research data, including large and complex data types

- gold Open Access which fosters wider collaboration and increased citations

- maximum visibility for your research: over $100 \mathrm{M}$ website views per year

At $\mathrm{BMC}$, research is always in progress.

Learn more biomedcentral.com/submissions 